\title{
POSSIBILITIES OF SPATIAL HEARING TESTING IN OCCUPATIONAL MEDICINE
}

TOMASZ PRZEWOŹNY

\author{
Medical University of Gdańsk, Gdańsk, Poland \\ Department of Otolaryngology
}

\begin{abstract}
Dysfunctions of the organ of hearing are a significant limitation in the performance of occupations that require its full efficiency (vehicle driving, army, police, fire brigades, mining). Hearing impairment is associated with poorer understanding of speech and disturbed sound localization that directly affects the worker's orientation in space and his/her assessment of distance and location of other workers or, even most importantly, of dangerous machines. Testing sound location abilities is not a standard procedure, even in highly specialized audiological examining rooms. It should be pointed out that the ability to localize sounds which are particularly loud, is not directly associated with the condition of the hearing organ, but is rather considered an auditory function of a higher level. Disturbances in sound localization are mainly associated with structural and functional disturbances of the central nervous system and occur also in patients with normal hearing when tested with standard methods. The article presents different theories explaining the phenomenon of sound localization, such as interaural differences in time, interaural differences in sound intensity, monaural spectrum shape and the anatomical and physiological basis of these processes. It also describes methods of measurement of disturbances in sound localization which are used in Poland and around the world, also by the author of this work. The author analyzed accessible reports on sound localization testing in occupational medicine and the possibilities of using such tests in various occupations requiring full fitness of the organ of hearing.
\end{abstract}

Key words:

Spatial hearing, Directional hearing, Sound localization, Hearing testing in workers, Auditory fitness for duty, Hearing impairment

\section{INTRODUCTION}

Employees working in particularly noisy work environments can be exposed to the risk of disturbances in localizing significant sources of sounds, such as machines or dangerous equipment. Each year severe accidents take place in workplaces due to workers' problems with localizing alarming sources of sounds [1-3].

Professionals for whom the organ of hearing is absolutely crucial include vehicle drivers, pilots, soldiers, police officers, street wardens, firemen, miners, air and ground traffic control workers, workers exposed to the risk of falling from heights (heavy equipment operators, controllers) and even professional musicians [4-7]. In order to perform these professions, they also need to have sufficient sensitivity of hearing and its symmetry, which is even more important for maintaining normal directional hearing [8].

In the auditory fitness for duty (AFFD) assessment in Poland we take into account the results of pure-tone audiometry, which do not enable examination of many auditory phenomena taking place at workplaces, such as the noise, movement of machines and co-workers creating

Received: December 10, 2014. Accepted: July 14, 2015.

Corresponding author: T. Przewoźny, Medical University of Gdańsk, Department of Otolaryngology, Smoluchowskiego 17, 80-214 Gdańsk, Poland (e-mail: tprzew@gumed.edu.pl). 
a constantly changing acoustic environment. Modern methods for evaluating these parameters include, among others, Hearing in Noise Test (HINT) and sound localization testing $[9,10]$. The aim of this article is to present the basis of the phenomenon of sound localization, the history of testing methods in Poland and worldwide (with particular focus on the method used by the author) and an overview of possibilities to apply these studies in occupational medicine.

\section{THEORIES OF SOUND LOCALIZATION}

Studies aimed at explaining the phenomenon of sound localization date back to as early as the 19th century. In 1896, Lord Rayleigh [11] noticed that humans are able to use the phenomenon of interaural time difference (ITD) in pure-tone localization (Figure 1a).

This theory was developed at the beginning of the 20th century by von Hornbostel and Wertheimer [12], who found that time difference needed for the subject to detect that the source of sound has moved by $90^{\circ}$ to the side in the direction of the earlier stimulated ear is $630 \mu \mathrm{s}$. The difference mainly depends on the size of the subject's head [13]. The largest ITD that can be caused by a typical human head for sound sources in free field is therefore called the Hornbostel-Wertheimer constant and is approx. $2 \mathrm{~ms}$ [14].

This theory was further developed and supplemented by Matzker $[15,16]$ in the middle of the 20th century. He observed that at an interaural distance difference of $21 \mathrm{~cm}$, the shortest ITD needed for the alleged movement of sound source is on average $180 \mu$ s. This theory is also limited as regards the frequencies of the localized sound stimuli. The upper limit of ITD sensitivity is somewhere between $1300 \mathrm{~Hz}$ and $1450 \mathrm{~Hz}$ [17,18]; therefore, this mechanism is useless in localization of sounds at higher frequencies, just as in the case when the azimuth increases enough for the interaural phase difference (IPD) to become equal to $180^{\circ}$.
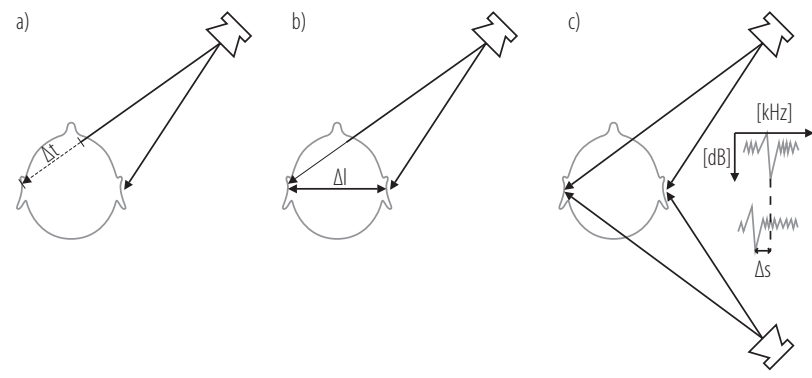

a) time difference $(\Delta t)$ between the moment the sound wave reaches both ears in the horizontal plane is useful for sounds of $\mathrm{f} \leq 1400 \mathrm{~Hz}$ frequency; b) the head shadow effect causes differences in sound wave intensity $(\Delta \mathrm{I})$ that reach both ears in the horizontal axis (the mechanism is useful for sounds of a frequency $\mathrm{f} \geq 1400 \mathrm{~Hz}$ ); c) differences in the spectrum of waves reaching the tympanic membrane $\Delta$ s according to the glancing angle (the mechanism is mainly useful in the vertical plane for stimuli of $\mathrm{f} \geq 4000 \mathrm{~Hz}$ ).

Fig. 1. Mechanisms of sound localization and major cues in spatial hearing: a) interaural time difference (ITD), b) interaural intensity difference (IID), and c) monaural spectrum shape (MSS)

Another mechanism explaining human ability to localize sound in space involves interaural intensity difference (IID) or interaural level difference (ILD) (Figure $2 b$ ). It is believed that Politzer was the first investigator to suspect the existence of that phenomenon. As early as in the 19th century, he observed that people with unilateral deafness have difficulties with assessing the origin of the sound source [19]. Moreover, he suspected that sound localization depends on differences in the intensity of the acoustic stimulus stimulating both ears. He noted that when examining subject's hearing with the use of a watch or acoumeter, one has to pay attention to the device's location, because the acuity of hearing depends on sound source location in relation to the subject's external auditory foramen [20].

This theory was further developed by Lord Rayleigh [21] in 1907, who named it "duplex theory." It says that the perceived azimuth angle of a sound source is dependent on cues provided by ITD and ILD. Sound localization is achieved by detecting and comparing the differences in 

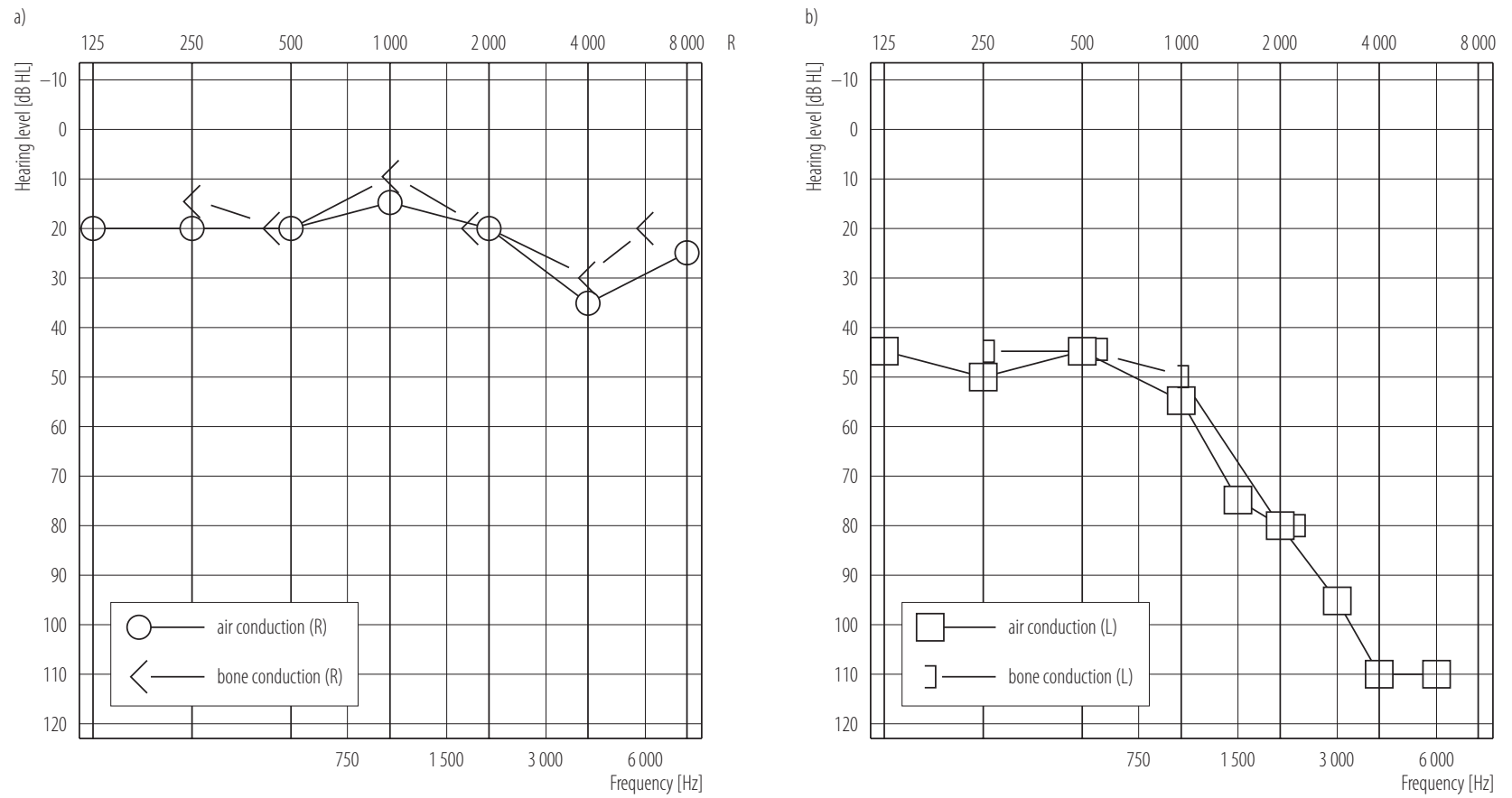

c)

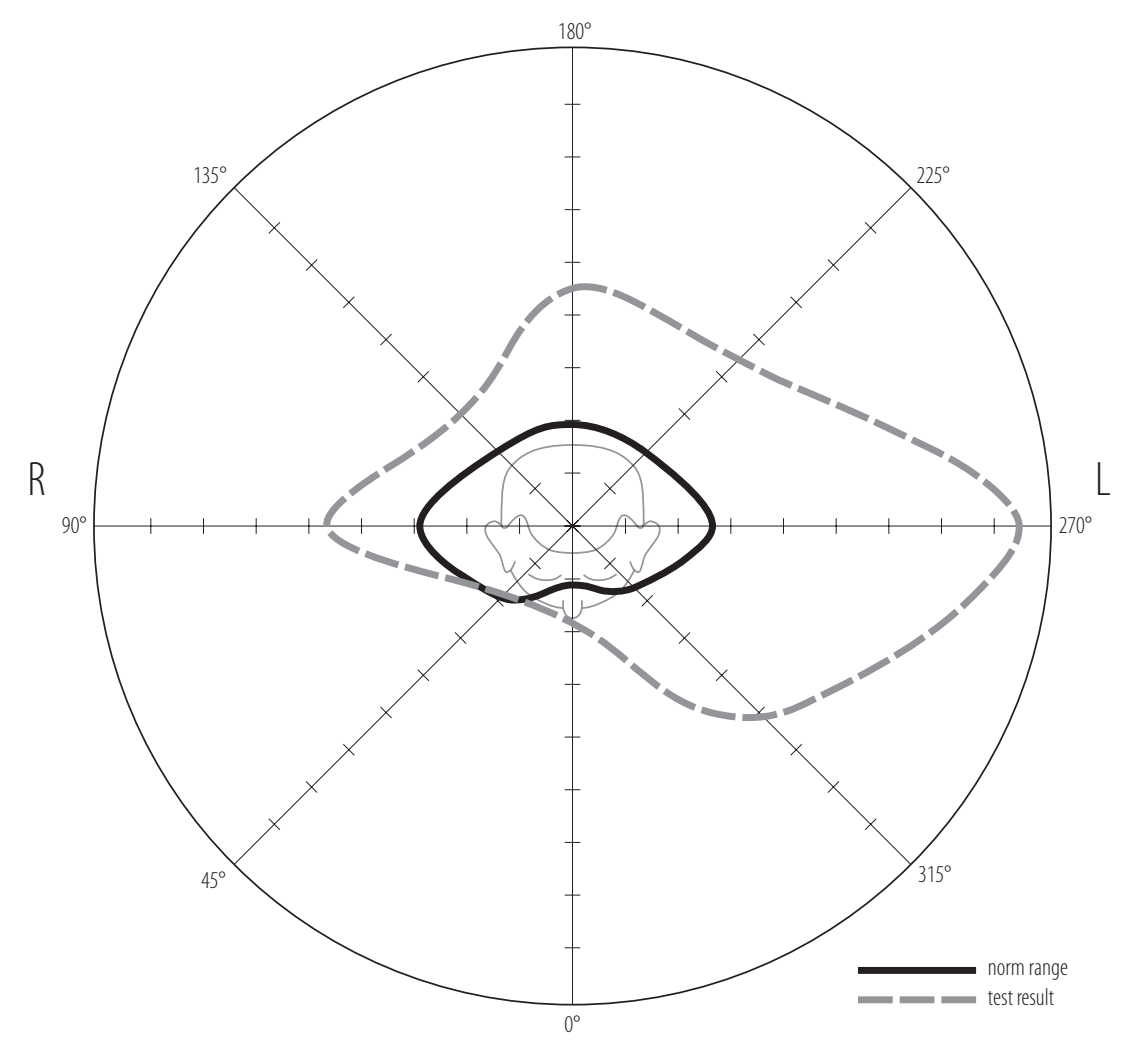

Fig. 2. Hearing test in a 59-year-old professional driver: a) pure-tone audiogram, right ear (R) (slight sensorineural hearing loss (HL), high-tone, cochlear), b) pure-tone audiogram, left ear (L) (severe sensorineural hearing loss, middle and high-tone (slope type), retrocochlear), and c) obvious disturbance of sound localization mainly at the left side (azimuths $225^{\circ}, 270^{\circ}, 315^{\circ}$ ) and the back of the head (azimuth $180^{\circ}$ ) 
tympanic membrane vibrations for narrowband sound-frequency channel in the horizontal plane. Crucial is the head shadow effect, which creates significant differences in the intensity of the stimulus reaching both ears. This phenomenon is characteristic of sound waves almost equal or shorter than the diameter of the head and is mainly used in the detection of differences in the horizontal plane for tones of a frequency higher than $1.4 \mathrm{kHz}[22,23]$.

Both the ITD and the IID phenomena provide reliable information about the position of the sound source in the right-left horizontal plane. However, they do not explain the differences in the position of this source in the front-back, up-down sagittal plane.

The ability to localize sounds along these planes requires monaural spectrum shape (MSS) or monaural cues (MC) (Figure 1c). Sound localization in the front-back sagittal plane and the up-down horizontal plane is primarily determined by monaural cues.

Despite the fact that the theories of ITD and IID, collectively referred to as the "duplex theory" quite effectively explain the phenomenon of sound localization, they do not explain it in the region called the "cone of confusion" a cone whose apex is on the auricle and the long axis goes along the line joining the subject's ears. Sounds in the cone have the same ITD and IID [24]. This is why a different mechanism is needed defining sound localization.

Monaural cues are directionally dependent on spectral changes, which are produced due to reflections of sound waves from the folds of the auricle. Monaural and binaural cues are known as the head-related transfer function (HRTF). This phenomenon mainly pertains to sounds of a frequency higher than $4 \mathrm{kHz}$. Thus, the more such high-frequency elements in the sound, the more the monoaural cues are used in the analysis of its position $[13,25,26]$. It is possible to localize the position of the sound source in a horizontal plane with one ear, which takes place in a unilateral deafness. However, the minimum audible angle (MAA) resulting from it amounts to approx. $30-40^{\circ}$ and is 10 times higher than in healthy people. This is why for complete sound localization ITD, IID and MC are needed. Monaural cues depend on the original sound signal, so in order to interpret them, one needs to know it better. Additional information can be supplied from a slight head movement. If the duration of $\mathrm{MC}$ is at least $500 \mathrm{~ms}$, which is sufficient for head movement, it helps the listener to localize the sound by changing the head position in space (the so-called pricking up one's ears) [27].

\section{SOUND LOCALIZATION TESTING AROUND THE WORLD}

First reports about sound localization in people were authored by Giovianni Battista Venturi (1746-1822), who suggested that it resulted from an asymmetry of ear. However, clinical application of this phenomenon took place much later [28]. Sound localization was first studied by Politzer [19]. He used the method of identification of the location of sound source by subjects pointing at it with a finger or hand. His successors introduced describing sound source location with words.

In 1938, Wilska [29] used 2 loudspeakers, which were moved closer and further to each other around a circle, with the subject sitting inside the circle. The result of the test was the angle between the radiuses joining the center of the circle with the positions of the loudspeakers. In 1950, Duyff et al. [30] suggested to use a method in which the loudspeaker on a pendulum was moved in a plane parallel to the frontal plane of the subject.

In 1957, Matzker [16] developed the theory of time differences and introduced a system in which sound localization was investigated using headphones and signal time delay. In 1958, Mills [23] proposed a method using minimum audible angle (MAA) defined as the smallest detectable difference between the azimuths of 2 identical sources of sound. He evaluated the perception of small changes of the sound direction for several azimuths in the first 
quadrant $\left(0-90^{\circ}\right)$. The result of the test was just noticeable change (depending on the original location of the source of sound) of the angle from which the sound was localized by the subject. This enabled quantitative evaluation of the phenomenon of sound localization (angular values). In the same year, Sanchez-Longo et al. [31] used an ophthalmological perimeter with an audiometer's headphone placed in 13 different positions. The result was the angle indicated by the subject in relation to the real position of the sound source and the final result was an arithmetic mean value of the measurements for 13 different azimuths. The value of $12^{\circ}$ was considered a normative value. The angle at the right and left side and the difference between both sides were also determined. In 1983, Häusler et al. [8] used MAA earlier reported by Mills [23], analyzed with a movable loudspeaker. They also measured ITD and IID with headphones in the same investigation and specified disturbances of localization in different pathologies of the middle ear, inner ear and the auditory pathway, providing normative values for the interpretation of these studies. Later studies carried out by other authors did not significantly differ from the ones presented above.

\section{SOUND LOCALIZATION TESTING IN POLAND}

Studies of sound localization in Poland were started in 1936 by Zakrzewski [32] and were later continued in the Clinical Hospital in Poznań. Zakrzewski placed 13 loudspeakers around a hemisphere and the subject seated in the center on the rotatory armchair had to point with his hand and verbally describe the position of the sound source. In 1960 he modified his previous measuring system and limited the number of loudspeakers to just one placed in front of the subject seated on a calibrated swivel chair that was turned around during the test [33]. The smallest angle between 2 positions of the loudspeaker (difference between the reference position and the position when the subject recognized that the second signal came from different place in the space) was called the angle of directional hearing acuity (ADHA). The method of measuring the angle of directional hearing acuity was then used in Poland.

In 1964, Pruszewicz and Gerwel [34] observed good sound localization in blind patients, while Szmeja and Gerwel [35] found out that the ability to localize sounds deteriorates with age in people older than 50. This phenomenon was confirmed by Kruk-Zagajewska [36] in a group of 315 patients aged $15-80$ years. Additionally, she found no differences in the results obtained in the ADHA test (angle of directional hearing acuity) between men and women [36]. Also, percentile normative values for this examination were established in a large group of subjects [37].

In 1972, Pruszewicz and Kosowicz described disturbances of sound localization in patients with adrenal insufficiency [38]. In 14 out of 29 patients they found ADHA values higher than in healthy subjects at the same age. In 1979, Pruszewicz and Świdziński investigated sound localization using the method of time differences between acoustic stimuli [39]. They used TDH 39 headphones powered with a signal from a two-channel audiometer or 2 generators of a sine wave and sough. Time delay $(\Delta t)$ in their method was $0.01-0.5 \mathrm{~ms}$, which was consistent with movement of the source of sound $0-50^{\circ}$. The subject was asked to identify the ear to which the ostensible source of sound was lateralized at the same signal intensity in both ears.

Another Polish investigator of sound localization was Kołdej [40]. He used a trainer of directional hearing consisting of 8 loudspeakers located in a circle of $10 \mathrm{~m}$ in diameter. The subject seated in the center was asked to mark at the device where the signal was coming from (pure-tone pulses: $0.5 \mathrm{kHz}, 2 \mathrm{kHz}, 4 \mathrm{kHz}$ ). The author observed that there was a possibility to improve the abilities of sound source localization by using appropriate exercises which can be applied in the army or the police.

In 1995, Niewiarowicz et al. [41] studied the angle of directional hearing acuity (ADHA) using a measuring set 
similar to the one used by Mills [23] and Zakrzewski [33], by moving the signal-emitting loudspeaker on a pendulum within a range of $\pm 30^{\circ}$. The measurement was repeated with the listener's position changing clockwise in the range of $0-360^{\circ}$, in $45^{\circ}$ steps. The authors pointed out that the difference between ADHA and MAA pertained only to the way in which the loudspeaker was moved only to the right in ADHA and in both directions in MAA. Additionally, they observed the best sound localization at the $0^{\circ}$ azimuth for noise signals and the poorest one at azimuths $90^{\circ}$ and $270^{\circ}$ for sinusoidal signals.

In 2007, Przewoźny et al. [42,43], following the example of the experiments by Mills [23], Häusler [8], Zakrzewski [33], and Niewiarowicz et al. [41] built a device for MAA measurements using pure-tone stimuli. He used the device to examine patients with hearing disturbances after ischemic cerebral stroke. Based on this device, Gromnicki et al. [44] used localization testing in patients with sudden deafness. The author of this paper has been using the MAA method of sound localization proposed by Mills [23] since 2006, which is described below in details.

\section{MINIMUM AUDIBLE ANGLE TEST (MAAT)}

The estimation of horizontal minimum audible angle test was carried out using broad-band noise bursts with a relatively flat spectrum $12.5-20000 \mathrm{~Hz}$. The signal was presented in sets of two 1-s bursts, separated by 2.5 -s breaks with rise-fall time of $50 \mathrm{~ms}$ and $85 \mathrm{~dB}$ sound pressure level (SPL). Signals were reproduced from a CD player and after amplification transmitted to the loudspeaker set. The measurement was made in the free-field in the horizontal plane at 8 equally spaced angles (every $45^{\circ}$ ) around the head for azimuths: $0^{\circ}, 45^{\circ}, 90^{\circ}, 135^{\circ}, 180^{\circ}, 225^{\circ}, 270^{\circ}$, $315^{\circ}$ and each time calculating average angle value. The test was performed in a sound-proof booth. The measuring set consisted of the following items presented in Photo 1.

Sound level meter, type 2250, G4 (Brüel \& Kjær, Denmark) was used to estimate sound pressure level in the

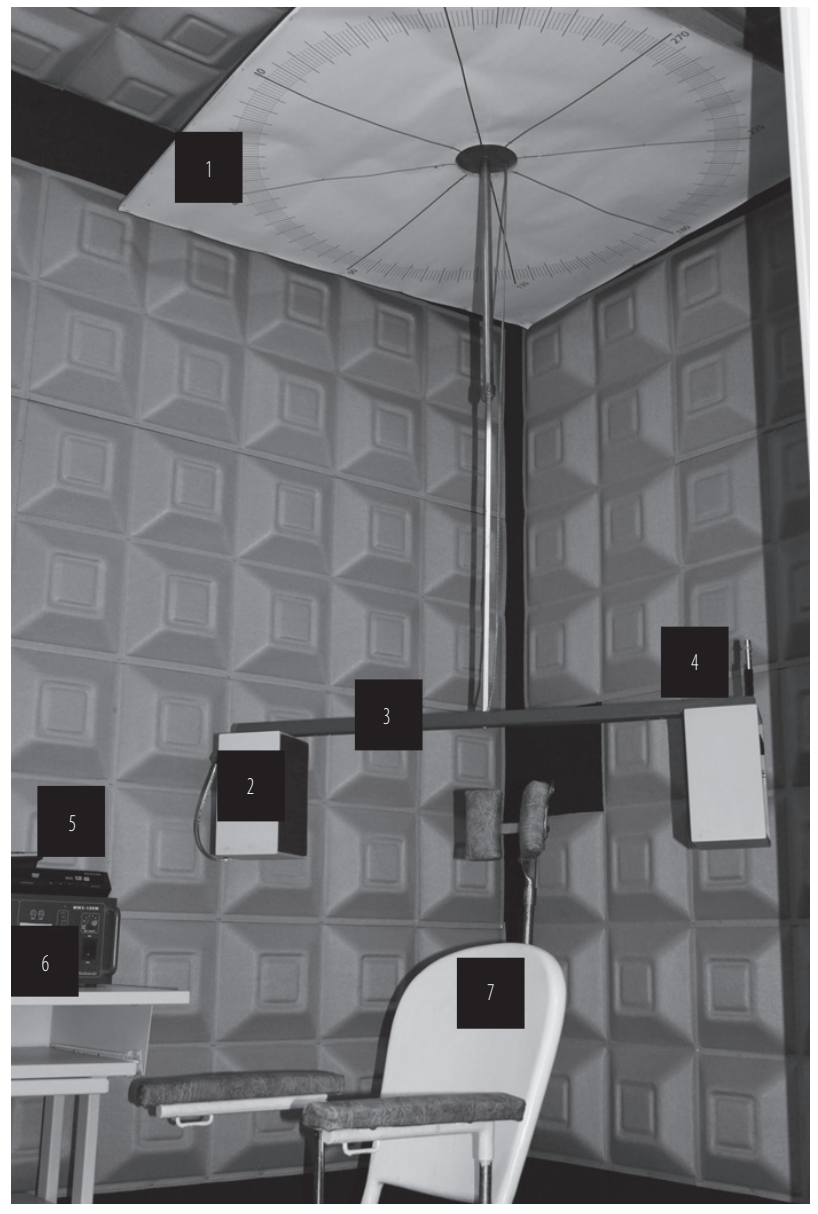

1 - calibrated board with an angular scale $\left(0-359^{\circ}, 8\right.$ medial azimuths: $\left.0^{\circ}, 45^{\circ}, 90^{\circ}, 135^{\circ}, 180^{\circ}, 225^{\circ}, 270^{\circ}, 315^{\circ}\right) ; 2$ - set of FF25 type B class 1 loudspeakers (Siemens, Denmark); 3 - metal pendulum for moving the set of loudspeakers; 4 - laser pointer; 5 - DVD/CD-S295 player (Panasonic, China) ; 6-MW3-150W amplifier with a graphic equalizer $\pm 12 \mathrm{~dB}$ (Rduch Elektroakustyka, Poland); 7 - metal chair with head stabilizer.

Photo 1. Set for the minimum audible angle (MAA) testing view from sound-proof booth

point of the investigated person's ear. The measuring set was calibrated using 5-s sound balanced level in dB SPL. The metal arm moved to the front of the loudspeaker set. Loudspeakers were immovable; one of them was active and the other one was passive, serving only as a counterweight and it did not emit any sound.

The metal arm was attached to the ceiling of the study room with a metal pin, and its height was adjustable. 
A laser pointer was attached to the passive loudspeaker, which measured the angle of sound acuity every $1^{\circ}$ on a scaled table. The distance from the active speaker to the center of the subject's head was fixed at $60 \mathrm{~cm}$. The speaker was always directed towards the subject and it was unchangeable.

While being examined, the patient was seated and blindfolded with his eyes closed in order to eliminate visual cues. The subject was seated on a metal armchair with his head immobilized by a shifting metal head holder. The measurements were made for azimuths $45^{\circ}, 90^{\circ}$ and $135^{\circ}$ (the examined person was seated so that his right ear was facing the active speaker) and for azimuths $225^{\circ}, 270^{\circ}$ and $315^{\circ}$ (the examined person was seated so that his left ear was facing the active speaker). For azimuth $0^{\circ}$ the speaker was situated in front of the tested person's head and for azimuth $180^{\circ}$ it was placed behind the subject.

The examination was commenced from azimuth $0^{\circ}$ onward (counter-clockwise) and finished for azimuth $315^{\circ}$. Every time, the point of reference was one of the 8 azimuths used. At each of all 8 azimuths, measurements were made with a movement of the sound source to the right and to the left, and the final result was the arithmetic mean value of both of these results, just as in the method proposed by Mills [23].

Each test was preceded by a short training and several examinations at the azimuth of $0^{\circ}$ with eyes open and closed, with a large movement of the loudspeaker in order to teach the subject proper discrimination of the location of the sound source. The first signal was emitted on the tested azimuth and the second one onward every $1^{\circ}$ in each cycle. The examined person was instructed to inform verbally ("from 2 places" vs. "from 1 place") when the second signal was noted in another point of space. That value on angles was noted in a special form as a MAA for each azimuth (to the right, to the left, final MAA).

The MAA was measured at each of the 8 azimuths. The difference was gradually increased on successive trials until the subject replied "from 2 places" for deviation to the left and to the right compared to the reference azimuth. The investigator then increased the difference until the subject responded "from 1 place." After several increasing-decreasing sequences, the investigator was able to estimate the value of MAA.

In order to identify standard values, 60 healthy volunteers with normal hearing and no neurological medical history were selected, 10 per every age group. In accordance with the recommendations by Kruk-Zagajewska, the upper border was established at 95 percentile of controls and all the results were compared with this normative value [37]. The results were also presented graphically (Figure 2).

\section{SOUND LOCALIZATION TESTING IN OCCUPATIONAL MEDICINE}

In our residential and occupational urban environment, we are faced with a lot of frequently contradictory sound information, which has to be properly received and analyzed by our organs of hearing and the central nervous system.

Sound localization, which is considered one of highest hearing abilities, is also one of the most sublime mechanisms allowing us to avoid dangers. While in occupational medicine pure-tone and verbal audiometry remains the most important method of evaluation of the hearing organ, sound localization testing is performed rather rarely.

Vaillancourt et al. [7] reported that some organizations, such as the Royal Canadian Mounted Police, in addition to pure-tone audiometry, have included additional hearing tests in their Auditory Fitness For Duty (AFFD) examinations, such as the Hearing in Noise Test (HINT) and sound localization tests. These authors present the results of hearing tests in 57 officers using hearing aids. They investigated speech recognition and sound localization tasks in the left/right and front/back horizontal planes. Studies showed that use of a hearing aid neither significantly improved nor impeded left/right localization and 
substantially increased front/back errors in localization. They also pointed to the poor ability of pure-tone threshold data to predict functional ability for sound localization, which is consistent with the results obtained by other authors $[8,42]$.

It was observed that use of a hearing aid significantly impaired the front/back localization abilities in many subjects. To examine sound localization, the investigators used the System for Evaluating Sound Localization Ability (SELA) [7]. The system was built of 11 loudspeakers located at a half of a circle, at a distance of $1 \mathrm{~m}$ from the subject and spaced from one another at $15^{\circ}$. The subjects had to identify the number of the loudspeaker which was emitting the signal. The investigators used signals of $65 \mathrm{dBA}$ (or louder) broadband noise $(0.25-8 \mathrm{kHz})$ lasting $0.25 \mathrm{~s}$ in a horizontal plane. Localization was assessed with the loudspeaker placed behind, to the right, and to the left of subject. Normative values for this test provided by the authors (angular error in degrees) were $5.9^{\circ}$ for the azimuth of the loudspeaker in front of the subject's head, $11^{\circ}$ for the one at the right side and $10.7^{\circ}$ for the one at the left side. They were similar to the ones used by the author of this article in the MAA test, however, the normative values were divided depending on the age group using the percentile method.

It should be pointed out that standard values of the SELA test are close to the angular separation between adjacent loudspeakers in this measuring set. Sound localization by subjects wearing a hearing aid was better even without it for the sound sources placed at the back compared to those located at the sides, with much fewer left/ right than front/back errors. The values of the mean angular error were highest for the test from the side in subjects with a hearing aid.

In 1996, Punch et al. [45] observed that in the work of police law enforcement officers, the life and health of the employees can depend on their ability to properly hear, localize and understand the sounds surrounding them, including speech. While analyzing the criteria used during recruitment to task force, they found out that sound localization was not assessed as a separate hearing function. In recruitment to special forces, the symmetry of hearing was taken into consideration, and good sound localization ability was considered as a factor that can have multiple applications in various professional tasks. Pure tone audiometry and more and more frequently speech recognition in sound-free field both in silence and in noise find their applications in qualification tests for job positions which require a particularly effective acuity of hearing. Tests in free hearing field eliminate the differences between the aided and unaided workers. This is not possible in the case of standard pure-tone audiometry. Sound localization abilities are in this method specified only additionally, to a limited extent, mainly in the context of hearing symmetry. This could be justified by limited availability of appropriate devices, well-trained staff and, first of all, lack of uniformity of testing methods, which exist only in few centers and are used for scientific rather than commercial purposes. During AFFD assessment of particular candidates, routine methods should be applied which are used in audiological clinics.

Noise at a workplace is a significant factor, frequently underestimated in routine examinations of the organ of hearing. It adversely affects speech understanding and sound localization.

An interesting simulation of disturbances in sound localization in a noisy workplace was made by Laroche [1]. She described the effect of a warning siren placed on a travelling crane in a steel plant. The siren was producing sound signals of $600-1250 \mathrm{~Hz}$ frequency, was moving with the overhead crane and worked in a noisy environment where the noise reached 100-110 dBA. The worker - a burner operator, was wearing earplugs and a face protector. The author summarized the conditions at the workplace and noticed that the localization of the siren was in most cases incorrect. The cause of it was that its signal frequency was too low, 
since in the vertical plane people localize high-frequency (more than $4 \mathrm{kHz}$ ) signals most efficiently.

Another significant problem is the noise-induced hearing loss in such workplaces. Noise was a significant factor disturbing the localization of the siren, since the siren's sound level should be 10-15 $\mathrm{dB}$ higher than the background noise. In such a noisy workplace as a foundry, this difference of sound level is difficult to achieve. Additionally, the worker used ear plugs, and this type of hearing protectors can compromise hearing localization.

Another factor determining localization of sound signals in noise are the differences in personal perceptual abilities [46]. The noise itself can also mask the beginnings of sounds by reducing tips crucial for localization. Due to a sudden development of motorization, the noise in the streets has significantly increased. Moreover, drivers tend to look for more and more sound systems to equip their cars with. Also, new technologies associated with directional hearing are being introduced. When driving a vehicle, the driver may experience problems with sound localization and speech understanding because his interlocutor is usually sitting at the back or at the driver's side. The noise inside the lorry's cabin amounts to 61.2$78.7 \mathrm{dBA}$ [47]. This is a very difficult listening environment. In such an environment, the driver increases his voice intensity and turns his head towards the passenger, which can be dangerous. Drivers with hearing defect have difficulty in having a conversation in a noisy environment and this is why they should be disqualified from the profession. To illustrate this problem, investigators presented the results of hearing examinations and sound localization tests of a 59-year-old professional taxi driver with asymmetric left-sided retrocochlear hearing loss and bilateral disturbances of sound localization (very severe at the poorlyhearing ear). The patient was operated for a small neurilemmoma of the left nerve VIII using retrosigmoidal craniotomy. After the procedure a severe aggravation of hearing was observed at the left side (Figure 2).
It turned out that modern technologies used in hearing aids, associated with sough reduction and improvement of speech understanding impair sound localization. Thus, they can adversely affect localization of such important sound sources as other vehicles (especially the priority ones) or sirens [48,49]. Similarly, individual hearing protection devices, especially the earmuffs, can disturb sound localization, especially those of high frequencies such as alarm sirens [50]. These signals are localized through an analysis of such cues as HRTF. Due to the role of the auricle in transmission and modulation of these signals and their relation to the auricle, covering it can severely disturb the mechanism of sound localization in the vertical and the front-back plane (Figure 1a).

Another work environment, which has not yet been well investigated as regards its effect on sound localization abilities in humans, is the underwater environment. Abilities in azimuth localization of the human organ of hearing in seawater have been studied for 8 azimuthal directions of a low-frequency $(<500 \mathrm{~Hz})$ sound. Poor front/ back localization has been observed, but accurate left/ right discrimination [51], the other way round compared to the air environment [8]. The studies can be useful for professional divers, who work in an environment of limited visibility and must communicate using electronic devices.

Testing sound localization abilities in workers aims at improving their safety in their work environment. Good sound localization abilities help workers avoid threats they are exposed to at their workplaces, especially if they work in noise, which significantly disturbs proper hearing, sound understanding and sound localization. Studies of sound localization are mainly limited by poor access to testing devices, large discrepancies in the methodologies and interpretation of test results and, first of all, difficulties in proper conduct of the test.

Another limitation is the need to establish normative values for particular methodologies of this test, which 
requires long-lasting studies on a population of patients who are audiologically and neurologically healthy. So far, sound localization testing has not been included in the AFFD standards. It should be pointed out that sound localization disturbances can be found in people with normal hearing threshold tested in pure-tone audiometry - so far the basic tool for the assessment of the organ of hearing in qualification tests for occupations requiring perfect acuity of hearing. As pointed out in reports, scientists see this problem and it will perhaps be solved in the future by introducing a new, simple and uniform method of measuring the sound localization abilities.

\section{ACKNOWLEDGMENTS}

Acknowledgements to Mr. Tomasz Zawistowski, a graphic designer from the "Directors" advertisement agency in Warszawa, Poland, for his technical help in creating Figure 1 and the angular scale for the medical equipment.

\section{REFERENCES}

1. Laroche C. Review of the literature on sound source localization and the applications to noisy workplaces. Can Acoust. 1994;22(4):13-8.

2. Moll van Charante AW, Mulder PG. Perceptual acuity and the risk of industrial accidents. Am J Epidemiol. 1990;131(4):652-63.

3. Palmer KT, Harris EC, Coggon D. Chronic health problems and risk of accidental injury in the workplace: A systematic literature review. Occup Environ Med. 2008;65(11):757-64, http://dx.doi.org/10.1136/oem.2007.037440.

4. Forshaw S, Hamilton K. Assessment of occupational hearing requirements. Can Acoust. 1997;25(1):3-9.

5. Śliwińska-Kowalska M. [Hearing screening criteria for the performance of hearing critical jobs]. Otorynolaryngologia. 2013;12(3):105-11. Polish.

6. Tufts JB, Vasil KA, Briggs S. Auditory fitness for duty: A review. J Am Acad Audiol. 2009;20(9):539-57, http://dx.doi. org/10.3766/jaaa.20.9.3.
7. Vaillancourt V, Laroche C, Giguère C, Beaulieu MA, Legault JP. Evaluation of auditory functions for Royal Canadian Mounted Police officers. J Am Acad Audiol. 2011;22(6):31331, http://dx.doi.org/10.3766/jaaa.22.6.2.

8. Häusler R, Colburn S, Marr E. Sound localization in subjects with impaired hearing. Spatial discrimination and interaural discrimination tests. Acta Otolaryngol. 1983;96(Suppl 400):1-62, http://dx.doi.org/10.3109/00016488309105590.

9. Giguère C, Laroche C, Soli SD, Vaillancourt V. Functionally-based screening criteria for hearing-critical jobs based on the Hearing in Noise Test. Int J Audiol. 2008;47(6):319-28, http://dx.doi.org/10.1080/14992020801894824.

10. Vaillancourt V, Laroche C, Mayer C, Basque C, Nali M, Eriks-Brophy A, et al. The Canadian French Hearing in Noise Test. Int J Audiol. 2008;47(6):383-5, http://dx.doi. org/10.1080/14992020802055300.

11. Strutt JW (Lord Rayleigh). The theory of sound. Dover ed. Vol. II. London: Macmillan and Co. Ltd.; 1896. p. 272.

12. Von Hornbostel EM, Wertheimer M. [On the perception of the direction of sound]. Sitzungsber Akad Wiss Berlin. 1920;15:388-96. German.

13. Blauert J. Spatial hearing with one sound source. In: Blauert J, editor. Spatial hearing: The psychophysics of human sound localization. Cambridge: The MIT Press; 1997. p. 36-200.

14. Hartmann WM, Macaulay EJ. Anatomical limits on interaural time differences: An ecological perspective. Front Neurosci. 2014;8:34, http://journal.frontiersin.org/Journal/10.3389/ fnins.2014.00034.

15. Matzker J. [Attempted explanation of aural determination of direction on the basis of super-sensitive recording of time differences]. Acta Otolaryngol. 1958;49(6):483-94, http:// dx.doi.org/10.3109/00016485809134779. German.

16. Matzker J. [The binaural test in space-occupying endocranial processes; a new method of otological diagnosis of brain disease]. Z Laryngol Rhinol Otol. 1957;36(4):177-89. German.

17. Zwislocki J, Feldman RS. Just noticeable differences in dichotic chase. J Acoust Soc Am. 1956;28(5):860-4, http://dx.doi. org/10.1121/1.1908495. 
18. Brughera A, Dunai L, Hartmann WM. Human interaural time difference thresholds for sine tones: The high-frequency limit. J Acoust Soc Am. 2013;133(5):2839-55, http:// dx.doi.org/10.1121/1.4795778.

19. Politzer A. [Studies of the paracusis loci]. Arch Ohren Nasen Kehlkopfheilk. 1876;11:231-6. German.

20. Politzer A, editor. [Treatise on the diseases of the ear]. Vol. I. Stuttgart: Verlag von Ferdinand Enke; 1878. p. 234. German.

21. Strutt JW (Lord Rayleigh). On our perception of sound direction. Philos Mag. 1907;13(74):214-32, http://dx.doi. org/10.1080/14786440709463608.

22. Nordlund B. Physical factors in angular localization. Acta Otolaryngol. 1962;54:75-93, http://dx.doi.org/10.3109/0001 6486209126924.

23. Mills AW. On the minimum audible angle. J Acoust Soc Am. 1958;30(4):237-46, http://dx.doi.org/10.1121/1.1909553.

24. Oldfield SR, Parker SPA. Acuity of sound localisation: A topography of auditory space. I. Normal hearing conditions. Perception. 1984;13(5):581-600, http://dx.doi.org/10.1068/p130581.

25. Katz BFG, Parseihian G. Perceptually based head-related transfer function database optimization. J Acoust Soc Am. 2012;131(2):99-105, http://dx.doi.org/10.1121/1.3672641.

26. Kulkarni A, Isabelle SK, Colburn HS. Sensitivity of human subjects to head-related transfer-function phase spectra. J Acoust Soc Am. 1999;105(5):2821-40, http://dx.doi. org/10.1121/1.426898.

27. Noble W. Auditory localization in the vertical plane: Accuracy and constraint on bodily movement. J Acoust Soc Am. 1987;82(5):1631-6, http://dx.doi.org/10.1121/1.395154.

28. Venturi JB. [Considerations on the knowledge of the extent that gives us the sense of hearing]. Mag Encyclop J Sci Lett Arts. 1796;3:29-37. French.

29. Wilska A. [Investigations of directional hearing]. Acta Soc Med Fenn Duodecim A. 1938;21:1-86. German.

30. Duyff JW, van Gemert AGM, Schmidt PH. Binaural sound location in the horizontal plane. Acta Physiol Pharmacol Neerl. 1950;1(4):540-61.
31. Sanchez-Longo LP, Forster FM. Clinical significance of impairment of sound localization. Neurology. 1958;8(2):11925, http://dx.doi.org/10.1212/WNL.8.2.119.

32. Zakrzewski A. [Experimental studies on functional asymmetry of hearing organ]. Pol Przegl Otolaryngol. 1936;12:21138. Polish.

33. Zakrzewski A. Clinical test for the acuity of directional hearing. Bull Soc Amis Sci (Med) (Poznan). 1960;10:7-14.

34. Pruszewicz A, Gerwel T. [Studies on the auditory localization in blind persons (measurement of the angle of acuity of directional hearing in a free auditory field)]. Otolaryngol Pol. 1964;18:231-4. Polish.

35. Szmeja Z, Gerwel T. [Apropos of the auditory localization in elderly persons studied in a free auditory field]. Otolaryngol Pol. 1964;18:223-9. Polish.

36. Kruk-Zagajewska A. [Measurements of the angles of directional hearing acuity in males and females with normal hearing]. Otolaryngol Pol. 1980;34(4):401-7. Polish.

37. Kruk-Zagajewska A. [Centile norms for evaluation of directional hearing in free acoustic field]. Otolaryngol Pol. 1981;35(1):27-33. Polish.

38. Pruszewicz A, Kosowicz J. [Changes in hearing adaptation and sound localization in patients with adrenal insufficiency]. Otolaryngol Pol. 1972;26(5):529-35. Polish.

39. Pruszewicz A, Świdziński P. [Study of sound localization by the method of time differences between acoustic stimuli]. Otolaryngol Pol. 1979;33(3):257-64. Polish.

40. Kołdej E. [Investigation in free acoustic field of the ability of directional hearing as a function of frequency and intensity of pure-tone signals]. Otolaryngol Pol. 1981;35(1):43-50. Polish.

41. Niewiarowicz M, Czajka J, Hojan E. Investigations on the angle of directional hearing acuity. Arch Acoustics. 2005 [cited 2014 Dec 3];30(2):147-57. Available from: http:// acousticsold.ippt.pan.pl/art/pdf/aa_30-2-01.pdf.

42. Przewoźny T, Narożny W, Stankiewicz C. Audiological symptoms in ischemic stroke. Eur Arch Otorhinolaryngol. 2007;264(Suppl. 1):208, http://dx.doi.org/10.1007/s00405007-0341-x. 
43. Przewoźny T. [Hearing condition of patients with early stage of ischemic stroke] [dissertation] [Internet]. Gdańsk: Medical University of Gdańsk; 2007 [cited 2014 Dec 3]. p. 27-9. Available from: http://pbc.gda.pl/Content/5306/przewozny_ tomasz_062267.pdf. Polish.

44. Gromnicki M, Narożny W, Kuczkowski J, Sochaczewska A. [The angle of directional hearing acuity in patients after the treatment of sudden sensorineural hearing loss]. Otorynolaryngologia. 2013;12(3):129-36, http://www.mediton. pl/library/orl_volume-12_issue-3_article-1121.pdf.

45. Punch JL, Robinson DO, Katt DF. Development of a hearing performance standard for law enforcement officers. J Am Acad Audiol [Internet]. 1996 [cited 2014 Dec 3];7(2): 113-9, http://www.audiology.org/sites/default/files/journal/ JAAA_07_02_08.pdf.

46. Andéol G, Macpherson EA, Sabin AT. Sound localization in noise and sensitivity to spectral shape. Hear Res. 2013;304: 20-7, http://dx.doi.org/10.1016/j.heares.2013.06.001.
47. Wu YH, Stangl E, Bentler RA, Stanziola RW. The effect of hearing aid technologies on listening in an automobile. J Am Acad Audiol. 2013;24(6):474-85, http://dx.doi.org/10.3766/ jaaa.24.6.4.

48. Van den Bogaert T, Doclo S, Wouters J, Moonen M. The effect of multimicrophone noise reduction systems on sound source localization by users of binaural hearing aids. J Acoust Soc Am. 2008;124(1):484-97, http://dx.doi.org/10.1121/1.2931962.

49. Van den Bogaert T, Klasen TJ, Moonen M, van Duen L, Wouters J. Horizontal localization with bilateral hearing aids: Without is better than with. J Acoust Soc Am. 2006; 119(1):515-26, http://dx.doi.org/10.1121/1.2139653.

50. Russell G. Limits to behavioral compensation for auditory localization in earmuff listening conditions. J Acoust Soc Am. 1977;61(1):219-20, http://dx.doi.org/10.1121/1.381261.

51. Savel S, Drake C. Auditory azimuthal localization performance in water as a function of prior exposure. Hum Factors. 2014;56(4):772-83.

This work is available in Open Access model and licensed under a Creative Commons Attribution-NonCommercial 3.0 Poland License - http://creativecommons.org/ licenses/by-nc/3.0/pl/deed.en. 